\title{
Antioxidant and Anti-inflammatory Activities of Different Solvent Extracts from Ipomoea pes-caprae (L.) R. Br. in Lipopolysaccharide Stimulated RAW 264.7 Macrophages
}

\author{
Chantarawan Saengkhae ${ }^{1, *}$, Napaporn Uawongyart ${ }^{2}$, Sunantha Osiri ${ }^{2}$, \\ Klaokwan Srisook ${ }^{3}$ and Marut Tangwattanachuleeporn ${ }^{4}$ \\ ${ }^{I}$ Research Unit in Proficient Laboratory for Natural Products, Faculty of Allied Health Sciences, \\ Burapha University, Chonburi 20131, Thailand \\ ${ }^{2}$ Faculty of Abhaibhubejhr Thai Traditional Medicine, Burapha University, Chonburi 20131, Thailand \\ ${ }^{3}$ Department of Biochemistry and Research Unit of Natural Bioactive Compounds for Healthcare \\ Products Development, Faculty of Science, Burapha University, Chonburi 20131, Thailand \\ ${ }^{4}$ Research Unit for Sensor Innovation, Burapha University, Chon Buri 20131, Thailand
}

("Corresponding author’s e-mail: chantars@buu.ac.th)

Received: 30 June 2020, Revised: 9 May 2021, Accepted: 30 May 2021

\begin{abstract}
The oxidative stress and inflammatory environment trigger an unhealthy circle, which can lead to various inflammatory diseases. Ipomoea pes-caprae, a traditional medicine mangrove plant, posed many pharmacological activities, including antioxidant, anti-inflammatory and anticancer effects. However, the possible mechanisms involved in Ipomoea pes-caprae are still unclear. This study aimed to investigate the antioxidant and anti-inflammatory effects of different solvent extracts from Ipomoea pes-caprae on lipopolysaccharide (LPS) stimulated macrophages. Three different solvent gradients were prepared orderly from non-polar to polar: hexane (Hex), supercritical fluid extraction using carbon dioxide plus EtOH as co-solvent $\left(\mathrm{SCO}_{2}\right)$ and ethanol $(\mathrm{EtOH})$. All 3 extracts were screened for the cytotoxicity on RAW264.7 cells by MTT assay. The non-toxic doses were investigated for reactive oxygen species (ROS) scavenging by DPPH and DCFH-DA assays and evaluated their anti-inflammatory activities via inhibition against LPS-induced nitric oxide (NO), prostaglandin $\mathrm{E}_{2}\left(\mathrm{PGE}_{2}\right)$, inducible $\mathrm{NO}$ synthase (iNOS) and cyclooxygenase-2 (COX-2) mRNA expression. All 3 extracts $(25-50 \mu \mathrm{g} / \mathrm{mL})$ exhibited DPPH scavenging and reduced intracellular ROS level in the order of $\mathrm{SCO}_{2}>\mathrm{EtOH}>\mathrm{Hex}$. Further, these extracts suppressed $\mathrm{NO}$ and $\mathrm{PGE}_{2}$ production by regulating iNOS and COX-2 mRNA expression in the order of $\mathrm{SCO}_{2}>\mathrm{Hex}>\mathrm{EtOH}$. Additionally, their inhibitory effects were in a similar pattern as the standard drugs L-NAME and celecoxib. These findings support the traditional use of Ipomoea pes-caprae in treating inflammatory diseases due to its attenuation of inflammation in activated macrophage. Also, a wide range of secondary metabolites in unique ecology may be useful as one of the alternative therapies for inflammatory diseases.
\end{abstract}

Keywords: Antioxidant, Anti-inflammatory, RAW264.7 cells, Lipopolysaccharide, Ipomoea pes-caprae

\section{Introduction}

Ipomoea pes-caprae (L.) R. Br., (Convolvulaceae) are distributed worldwide in tropical and subtropical coastal beaches. This plant has been used in traditional medicine to treat pain and various inflammation types, including jellyfish sting and dermatitis. Previous research works have confirmed the anti-inflammatory properties of this plant. In this context, the extract of petroleum ether showed considerable anti-inflammatory action when evaluated in different experimental models such as pawedema and ear-edema model, which were induced by carrageenan and arachidonic acid, respectively. The above-mentioned crude extract contained active compounds such as eugenol, (-)-mellein and 4vinylguaiacol, which exhibited anti-inflammation via the inhibition of prostaglandin activity [1]. The antinociceptive and anti-inflammatory effect of the hydroethanolic extract of the aerial parts was also reported using the writhing test and carrageenan-induced pleurisy models in mice with lower toxicity [2]. The ethanolic extracts from aerial parts showed anti-inflammatory activities in rats using the cotton pellet-induced granuloma model. The active substances were related to the presence of alkaloids, 
glycosides, flavonoids, tannins, and terpenoids [3]. In addition, the methanolic extract exhibited antinociceptive activity against acetic acid-induced abdominal constrictions and against formalin-induced pain in mice, which was equipotent to some analgesic drugs [4]. In a related study, the hydroethanolic extract relieved nociception and inflammation in mice that were injected with cnidarian venom into hind paw [5].

Free radicals in living systems can oxidize biomolecules such as DNA, proteins, lipids resulting in aging, inflammatory diseases, and cancer. Antioxidants are necessary for controlling degenerative diseases caused by reactive oxygen and nitrogen species [6]. The imbalance of antioxidants leads to various inflammatory-associated diseases by motivating the release of inflammatory mediators and cytokines. Chronic inflammation is associated with diseases due to its persistence of inflammation and various immune reactions, which can cause progressive damage. The active inflammatory cells can stimulate signal transduction cascades like inducible nitric oxide synthase (iNOS), cyclooxygenase-2 (COX-2), and various inflammatory cytokines, which will release more reactive oxygen species [7]. A role in oxidative stress-induced inflammation triggers a vicious circle, which after a long period of time may trigger carcinogenesis, degenerative diseases and metabolic syndromes [8,9]. Therefore, any antiinflammatory therapy would be most effective under these pathophysiological conditions. Thus, researchers have tried to find medicinal plants or their crude extracts that can perform both antioxidant and anti-inflammatory activities to inhibit various chronic inflammatory-associated diseases.

Another interesting action demonstrated by this plant was its ability to display cytotoxic activity. The hexane-soluble extracts have been demonstrated to have several inhibitory properties on the growth of tumor cell lines such as nasopharyngeal (KB), colon (HCT 15), squamous cell cervical (SQC-1 UISO), and ovarian (OVCAR) carcinomas [10]. The presence of alkaloids, flavonoids, tannins, terpenoids, and glycosides in the crude extract also have anticarcinogenic activities in mice melanoma cancer [11]. In a recent study, it has been shown that the hexane (Hex) and the supercritical fluid extraction by carbon dioxide $\left(\mathrm{SCO}_{2}\right)$ induced the $\mathrm{KB}$ cell apoptosis without causing excessive damage to normal human peripheral blood mononuclear cells (PBMC) [12]. Interestingly, several studies have demonstrated the significant level of inflammatory cytokines found in cancer microenvironment of various human cancers. However, the literature regarding the antioxidant, anti-inflammatory activities of this plant was not reported in respect of the production of reactive oxygen species (ROS), nitric oxide (NO) and prostaglandin $\mathrm{E}_{2}\left(\mathrm{PGE}_{2}\right)$ in the lipopolysaccharide (LPS) induced RAW 264.7 murine macrophage. In continuation of our research work, we investigated the antioxidant and anti-inflammatory effects of different solvent extracts from Ipomoea pes-caprae in LPS-stimulated RAW 264.7 cells as inflammatory model.

\section{Materials and methods}

\section{Preparation of plant extract}

The aerial parts of Ipomoea. pes-caprae (L.) R. Br were collected from Bang Saen Beach in Chonburi Province, Thailand during January-April 2015 and voucher specimen were deposited in the laboratory. After it was washed and oven-dried at $45^{\circ} \mathrm{C}$, hexane (Hex) and ethanol: water (50:50, v/v) $(\mathrm{EtOH})$ were macerated for 7 days and concentrated under vacuum on a rotary evaporator at $45{ }^{\circ} \mathrm{C}$. Supercritical fluid extraction was done using carbon dioxide plus $\mathrm{EtOH}$ as co-solvent $\left(\mathrm{SCO}_{2}\right)$ operated at 74 bar in combination with temperature at $31^{\circ} \mathrm{C}$ as our previous reported [12]. The crude extracts were stored at $-80{ }^{\circ} \mathrm{C}$ and dissolved in ethanol.

\section{Cell culture and viability assay}

RAW 264.7 cell, murine macrophage cell line was obtained from Assoc. Prof. Dr. Klaokwan Srisook. Cells were cultured in Dulbecco's modified Eagle's medium (DMEM) supplemented with $10 \%$ fetal bovine serum, $1 \%$ penicillin/streptomycin in a humidified atmosphere of $5 \% \mathrm{CO}_{2}, 95 \%$ air at 37 ${ }^{\circ} \mathrm{C}$. The cell viability was determined by using the 3-(4,5-dimethylthiazol-2-yl)-2,5-diphenyltetrazolium bromide (MTT) assay [12]. Briefly, cells were plated into 96 well plates at a density of $10^{5}$ cells/well and cultured at $37{ }^{\circ} \mathrm{C}$ for $24 \mathrm{~h}$. Then, cells were incubated with $1 \mu \mathrm{g} / \mathrm{mL}$ of LPS (from Escherichia coli 055:B5, Sigma) with or without various concentrations of test samples for $24 \mathrm{~h}$. Subsequently, a $10 \mu \mathrm{L}$ of the MTT $(5 \mathrm{~g} / \mathrm{L})$ was added to each well for $4 \mathrm{~h}$. The culture medium was removed, and the purple formazan crystals were dissolved in $100 \mu \mathrm{L} /$ well of dimethyl sulfoxide (DMSO) and measured at $570 \mathrm{~nm}$ using a microplate reader (Cecil Bioquest 2000 Series). Results were presented as a percentage of the control (100 \%) using: Absorbance $570 \mathrm{~nm}$ (sample)/Absorbance $570 \mathrm{~nm}$ (control) $\times 100$. 


\section{DPPH radical scavenging assay}

The scavenging activity of the stable 1,1-diphenyl-2- picrylhydrazyl (DPPH) free radical was carried out [13]. The test samples with various concentrations in ethanol $(20 \mu \mathrm{L})$ were mixed with $80 \mu \mathrm{L}$ of DPPH $(0.4 \mathrm{mM})$ in a 96 well microtiter plate and incubated at room temperature for $30 \mathrm{~min}$. The absorbance at $517 \mathrm{~nm}$ was measured with a microplate reader. The percentage inhibition activity was calculated from $[\mathrm{A}($ control $)-\mathrm{A}($ sample $) / \mathrm{A}$ (control) $] \times 100$, where $\mathrm{A}$ is the absorbance at $517 \mathrm{~nm}$. The inhibition curves were set and $\mathrm{IC}_{50}$ values were expressed as concentration to exert half of the scavenging activity.

\section{Measurement of intracellular ROS by DCFH-DA}

Intracellular ROS levels were detected using 2',7'-dichlorofluorescein diacetate (DCFH-DA) [14]. RAW 264.7 cells $\left(1 \times 10^{5}\right.$ cells/well) were seeded with culture medium for $24 \mathrm{~h}$ and then incubated with the test samples $0-50 \mu \mathrm{g} / \mathrm{mL}$ and/or LPS $(1 \mu \mathrm{g} / \mathrm{mL})$ for $24 \mathrm{~h}$. Then, the medium was changed to serumfree DMEM containing $10 \mu \mathrm{M}$ DCFH-DA and incubated for $30 \mathrm{~min}$ in the dark. After washing the cells with PBS for 2 times, the generation of dichlorofluorescein (DCF) resulting from oxidation of DCFH-DA in the presence of ROS was analyzed by flow cytometry using an excitation with a 488-nm argon ion laser (FACSCalibur, BD Biosciences, CA). Each sample were collected at least 10,000 cells.

\section{Measurement of NO}

RAW 264.7 cells $\left(1 \times 10^{5}\right.$ cells/well) were seeded into a 96 -well plate for $24 \mathrm{~h}$. Subsequently, the cells were treated with test samples $(0-50 \mu \mathrm{g} / \mathrm{mL})$ in the presence or absence of LPS $(1 \mu \mathrm{g} / \mathrm{mL})$ for $24 \mathrm{~h}$. The nitrite concentration in the culture medium was measured according to the Griess reaction [15]. The cell culture medium $(100 \mu \mathrm{L})$ was mixed with the same volume of Griess reagent (equal volumes of $1 \%$ $(\mathrm{w} / \mathrm{v})$ sulfanilamide in $5 \%(\mathrm{v} / \mathrm{v})$ phosphoric acid and $0.1 \%(\mathrm{w} / \mathrm{v})$ naphtylethylenediamine-HCl) and left for $10 \mathrm{~min}$ at room temperature. $N$-Nitro-L-arginine methyl ester hydrochloride (L-NAME, $250 \mu \mathrm{M}$ ), a non-selective nitric oxide synthase inhibitor, was used as a positive control. The absorbance was measured at $550 \mathrm{~nm}$ and the amount of nitrite in test samples was calculated using a sodium nitrite standard curve.

\section{Measurement of $\mathrm{PGE}_{2}$}

$\mathrm{PGE}_{2}$ were measured using an immunoenzymatic method according to the manufacturer's instructions. Briefly, RAW 264.7 cells $\left(1 \times 10^{5}\right.$ cells/well $)$ were incubated with test samples in the presence or absence of LPS $(1 \mu \mathrm{g} / \mathrm{mL})$ for $24 \mathrm{~h}$. Celecoxib $(20 \mu \mathrm{g} / \mathrm{mL})$, a selective COX-2, inhibitor, was used as a positive control. The concentration of $\mathrm{PGE}_{2}$ in the culture medium was determined using a specific enzyme immunoassay kit (Bio-Techne / R \& D Systems Inc., U.S.A.) against a PGE $_{2}$ standard curve [16].

\section{RNA extraction and real-time RT-PCR}

After treatment, total RNA from RAW 264.7 cells were isolated with the RNeasy Plus Mini Kit and RNA $(10 \mathrm{ng} / \mu \mathrm{L})$ reversely transcribed to cDNA with RT2 First Strand Kit according to the manufacturer's procedures (Qiagen company, Hilden, Germany). Reverse transcription- generated cDNA encoding iNOS, COX-2 and glyceraldehyde-3-phosphate dehydrogenase (G3PDH: internal standard) genes were amplified using real-time PCR by Taqman Probes (Applied Biosystems) following the manufacturer's recommendations. Relative quantification of gene expression was compared to housekeeping genes [17].

\section{Statistical analysis}

Data were expressed as the mean \pm SEM (standard error of mean) from 3 independent experiments. Significant differences among the mean of each group were determined using the one-way analysis of variance (ANOVA) with Dunnett's post hoc test. $P<0.05$ indicated a statistically significant.

\section{Results and discussion}

\section{Extraction}

In this study, $500 \mathrm{~g}$ of the dried plant was extracted by different solvents: Hexane, $\mathrm{CO}_{2}$ and ethanol: Water, respectively. The Hex extract was found having the highest yield $(2.9 \%)(\mathrm{w} / \mathrm{w})$, followed by EtOH $(1.9 \%)$ and $\mathrm{SCO}_{2}(1.3 \%)$. In our previous data [12], the phytochemical constituents were determined by gas chromatography-mass spectrometry (GC-MS), and the eugenol was chosen as markers because of its well-known anti-inflammatory and anticancer activities [18,19]. The $\mathrm{SCO}_{2}$ extract yielded 
the highest eugenol (3.19\%), which was higher than Hex (2.2\%) and EtOH (0.5\%). In literature review, Ipomoea pes-caprae consisted of various phytochemicals due to dissolve in specific solvents so it contains different active compound in various laboratories. Phenolic compounds such as flavonoids, phenolic acids and anthocyanins are the most secondary metabolites found in this plant [10,20]. Moreover, $\mathrm{CO}_{2}$ is an attractive solvent because it is non-toxic. Oxygen-free environments and supercritical fluid extraction utilize low temperatures, resulting in less deterioration of the active ingredients in this extract [21]. Being a natural source, Ipomoea pes-caprae may contain low side effects and benefit new drug discoveries.

\section{The effects of the 3 different solvent extracts from Ipomoea pes-caprae on cell viability}

The LPS $(1 \mu \mathrm{g} / \mathrm{mL})$ alone or the combine treatment between LPS plus Ipomoea pes-caprae extracts $(0-50 \mu \mathrm{g} / \mathrm{mL})$ did not affect the viability of the RAW264.7 cells as compared to control (Figure 1). However, EtOH, Hex and $\mathrm{SCO}_{2}$ extracts showed approximately 15 and $20 \%$ cytotoxicity at concentration $75-100 \mu \mathrm{g} / \mathrm{mL}$. According to these results, a series of non-toxic dose range $0-50 \mu \mathrm{g} / \mathrm{mL}$ of extract concentrations were chosen for their antioxidant and anti-inflammatory activities. A recent study by our group demonstrated that the same plant extracts exerted their cytotoxic effects on the human nasopharyngeal (KB) cells [12]. In addition, the compounds isolated from Ipomoea pes-caprae have also been reported to possess anticancer properties in many cancer cell lines [10,11]. However, these could be due to different in cell types, medium composition, treatment time and experimental conditions.

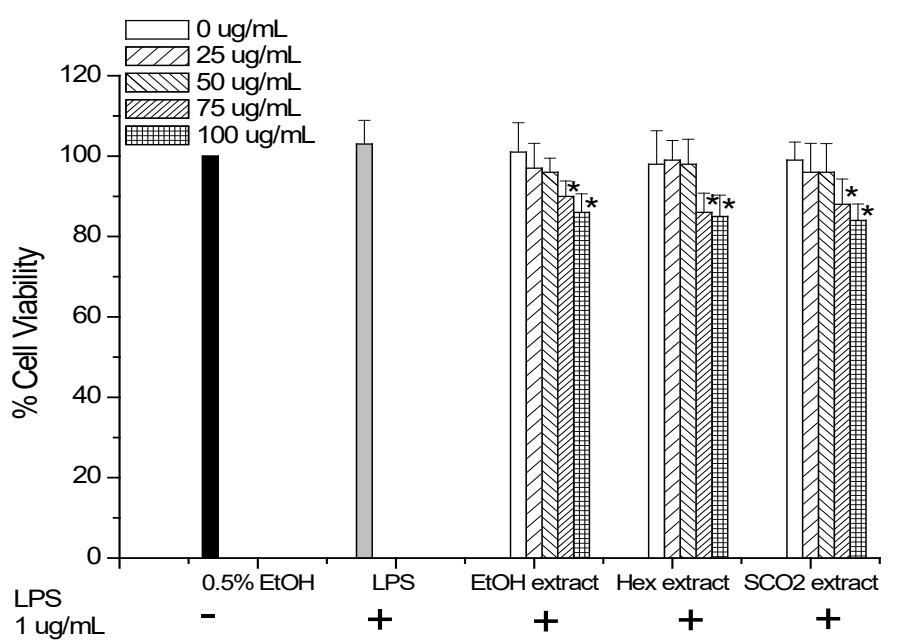

Figure 1 Effects of LPS and/or EtOH, Hex and $\mathrm{SCO}_{2}$ extracts $(0-100 \mu \mathrm{g} / \mathrm{mL})$ for $24 \mathrm{~h}$ on the viability of RAW 264.7 cells using MTT assays. Values are the means \pm SEM of 3 independent experiments. ${ }^{*} p<$ 0.05 indicated significant differences from the control group. activity

The effects of the 3 different solvent extracts from Ipomoea pes-caprae on DPPH scavenging

The free radical scavenging activity of the Ipomoea pes-caprae extracts was performed, and a concentration-response curve to DPPH assay was obtained in Figure 2. The highest scavenging was observed with $\mathrm{SCO}_{2}$ extract with an $\mathrm{IC}_{50}$ value of $9.82 \pm 1.17 \mu \mathrm{g} / \mathrm{mL}$ as different from the $\mathrm{IC}_{50}$ value of ascorbic acid $(4.45 \pm 0.66 \mu \mathrm{g} / \mathrm{mL})$, which is a well-known antioxidant. Hex and EtOH extracts showed scavenging activity with an $\mathrm{IC}_{50}$ value of $17.20 \pm 2.75$ and $25.14 \pm 4.27 \mu \mathrm{g} / \mathrm{mL}$, respectively. The stable DPPH radical contains an odd electron, which can accept an electron donated by an antioxidant compound. Consequently, DPPH test can be quantitatively measured radical scavenging action. In these results, the Hex extract was better than that reported by Banerjee et al. [22]. The antioxidant activities of many medicinal plants have a strong correlation with their phenolic compounds because its hydroxyl group donates hydrogen to form stable radical intermediates [23]. Nevertheless, it is also possible to study the in vitro antioxidant potential of Ipomoea pes-caprae extracts in terms of other experimental models such as measurement of intracellular ROS production. 


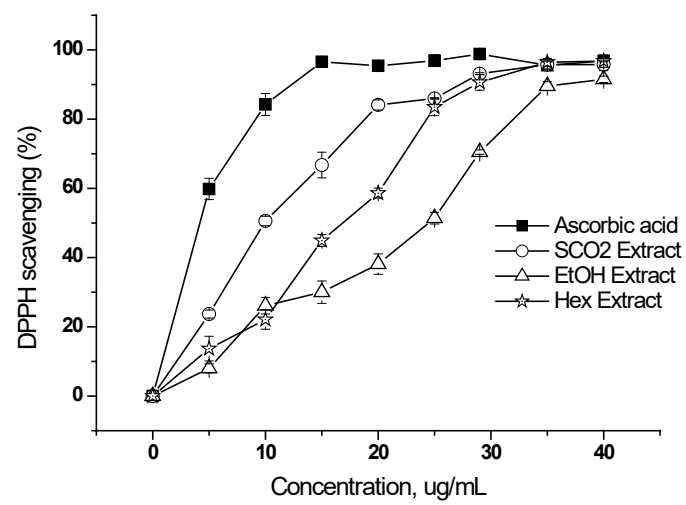

Figure 2 Effects of EtOH, Hex and $\mathrm{SCO}_{2}$ extracts on DPPH radical scavenging activity. Ascorbic acid was used as the positive control. Data were represented as the means \pm SEM of triplicate experiments.

The effects of the 3 different solvent extracts from Ipomoea pes-caprae on intracellular ROS

RAW264.7 cells were labeled with the ROS-sensitive fluorescence DCFH-DA that applied to viable cells. The non-fluorescent DCFH-DA dye penetrated the cell membrane and hydrolyzed by esterase to become DCFH [14]. In the presence of ROS, DCFH is oxidized to the fluorescent DCF that can be monitored by flow cytometer. As shown in Figure 3, LPS alone was found significantly increased in the ROS level compared to that in the untreated cells. The DCF fluorescent intensity in the LPS group was designated as $100 \%$ and used to calculate the relative expression of DCF fluorescence in other groups. Treatment of 3 different solvents of Ipomoea pes-caprae extracts at 25 and $50 \mu \mathrm{g} / \mathrm{mL}$ caused significant reduction of intracellular ROS level $(P<0.05)$. The inhibition percentage of ROS activity at a concentration of $50 \mu \mathrm{g} / \mathrm{mL}$ was in the order of $\mathrm{SCO}_{2}>\mathrm{EtOH}>\mathrm{Hex}$ with the percentage inhibition of 56.3 $\pm 5.68,47.6 \pm 8.24$ and $33.0 \pm 9.6 \%$, respectively. LPS produced ROS in macrophages via nicotinamide adenine dinucleotide phosphate oxidase (NADPH oxidase), resulting in ROS generation as indicated by the increase in DCF fluorescence [24]. Concomitant treatment with Ipomoea pes-caprae extracts were found inhibiting the LPS-induced ROS production. These results obtained from a cell-based antioxidant activity assay revealed consistency with the cell free DPPH radical system. Therefore, these results confirmed that Ipomoea pes-caprae extracts at non cytotoxic concentration scavenged free radicals in RAW264.7 cells. In addition, the oxidative damage to cellular components may lead to changes in the expressions of inflammatory mediators and cytokines, which are involved in inflammation-related diseases.
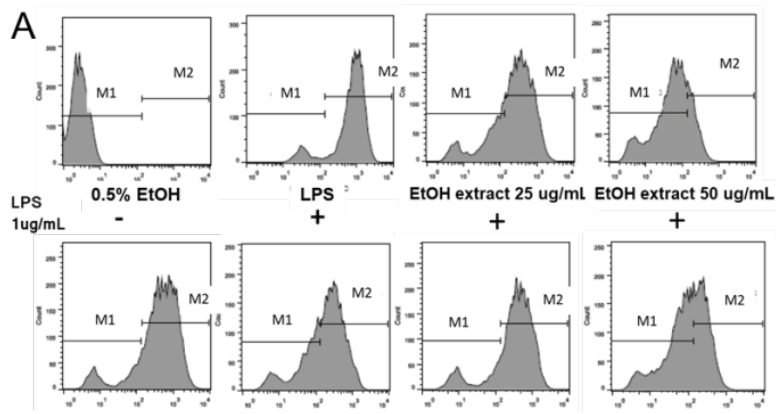

$+$

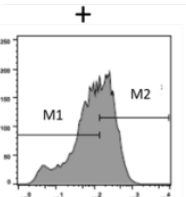

Hex extract
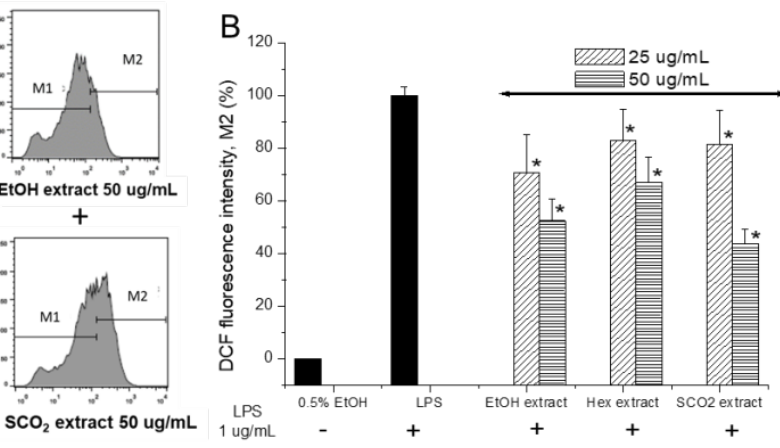

DCF fluorescence intensity

Figure 3 Effects of EtOH, Hex and $\mathrm{SCO}_{2}$ extracts on LPS induced ROS production in RAW 264.7 cells. The cells were incubated with $0-50 \mu \mathrm{g} / \mathrm{mL}$ of extractions in the presence or absence of LPS $(1 \mu \mathrm{g} / \mathrm{mL})$ for $24 \mathrm{~h}$. (A) One representative histogram of flow cytometry at indicated concentrations. (B) Mean fluorescence intensities (M2) \pm SEM of triplicate experiments. The LPS group was set to $100 \%$, and the values of other groups were reliable against it. ${ }^{*} P<0.05$ indicated significant differences from the LPStreated group. 
The effects of the 3 different solvent extracts from Ipomoea pes-caprae on NO and $\mathrm{PGE}_{2}$ production

The NO production was measured as nitrite as shown in Figure 4. When RAW 264.7 cells were treated with $1 \mu \mathrm{g} / \mathrm{mL}$ of LPS, the NO production increased to $32.4 \pm 5.33 \mu \mathrm{M}$ as compared to $2.22 \pm 0.22$ $\mu \mathrm{M}$ in the control cells without LPS. All 3 different solvent extracts $(25-50 \mu \mathrm{g} / \mathrm{mL})$ significantly reduced LPS-induced NO production $(P<0.05)$. EtOH, Hex and $\mathrm{SCO}_{2}$ extracts $(50 \mu \mathrm{g} / \mathrm{mL})$ significantly inhibited LPS-induced NO production to $16.4 \pm 3.42,13.34 \pm 1.47,11.1 \pm 1.05 \mu \mathrm{M}$, respectively with no cytotoxicity to the RAW 264.7 cells. The percentage of NO inhibition was equal to 50,59 and $65 \%$, respectively. The $\mathrm{PGE}_{2}$ production in LPS-induced RAW 264.7 cells were shown in Figure 5 indicating that LPS treatment $(1 \mu \mathrm{g} / \mathrm{mL})$ increased the amount of $\mathrm{PGE}_{2}$ formation $(1843 \pm 93 \mathrm{pg} / \mathrm{mL})$ as compared to untreated controls $(180 \pm 80 \mathrm{pg} / \mathrm{mL})$. Treatments with EtOH, Hex, and $\mathrm{SCO}_{2}$ extracts $(50 \mu \mathrm{g} / \mathrm{mL})$ inhibited LPS-induced $\mathrm{PGE}_{2}$ formation to $1351 \pm 96,1077 \pm 121,812 \pm 105 \mathrm{pg} / \mathrm{mL}$, respectively. The percentage of $\mathrm{PGE}_{2}$ inhibition was equal to 26,41 and $55 \%$, respectively. EtOH, Hex, and $\mathrm{SCO}_{2}$ extracts showed a similar pattern to that of inhibiting $\mathrm{NO}$ and $\mathrm{PGE}_{2}$ production in the LPS induced RAW 264.7 cells, and the relative effectiveness of these extracts was $\mathrm{SCO}_{2}>\mathrm{Hex}>$ EtOH. It has been well established that LPS, outer membrane of Gram-negative bacteria, activated the release of inflammatory mediators through toll like receptor 4 (TLR4) on the cell membrane of the macrophages. The overproduction of inflammatory mediators such as $\mathrm{NO}, \mathrm{PGE}_{2}$, interleukin (IL)-6, IL-1 $\beta$, and tumour necrosis factor (TNF)- $\alpha$ can damage the host, leading to various chronic inflammatory diseases. Thus, a decrease in the LPS induced expression of inflammatory mediators in macrophages may be useful for preventing the disease in association with inflammation [25].

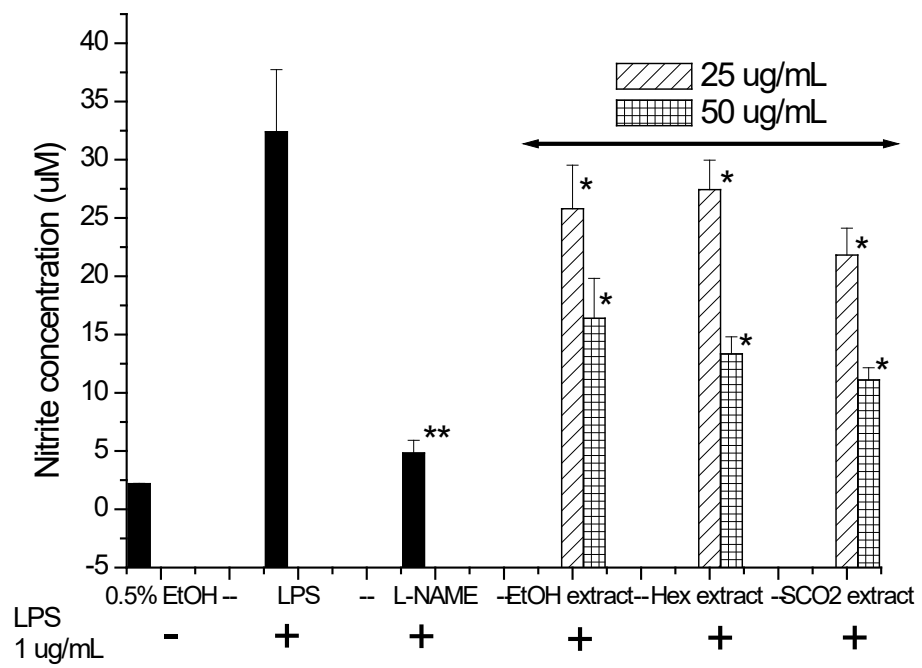

Figure 4 Effects of EtOH, Hex and $\mathrm{SCO}_{2}$ extracts on LPS induced nitrite production in RAW 264.7 cells. The cells were incubated with $0-50 \mu \mathrm{g} / \mathrm{mL}$ of extractions in the presence or absence of LPS $(1 \mu \mathrm{g} / \mathrm{mL})$ for $24 \mathrm{~h}$. L-NAME was used as the positive control. ${ }^{*} P<0.05$ and ${ }^{* *} P<0.01$ indicated significant differences from the LPS-treated group. 


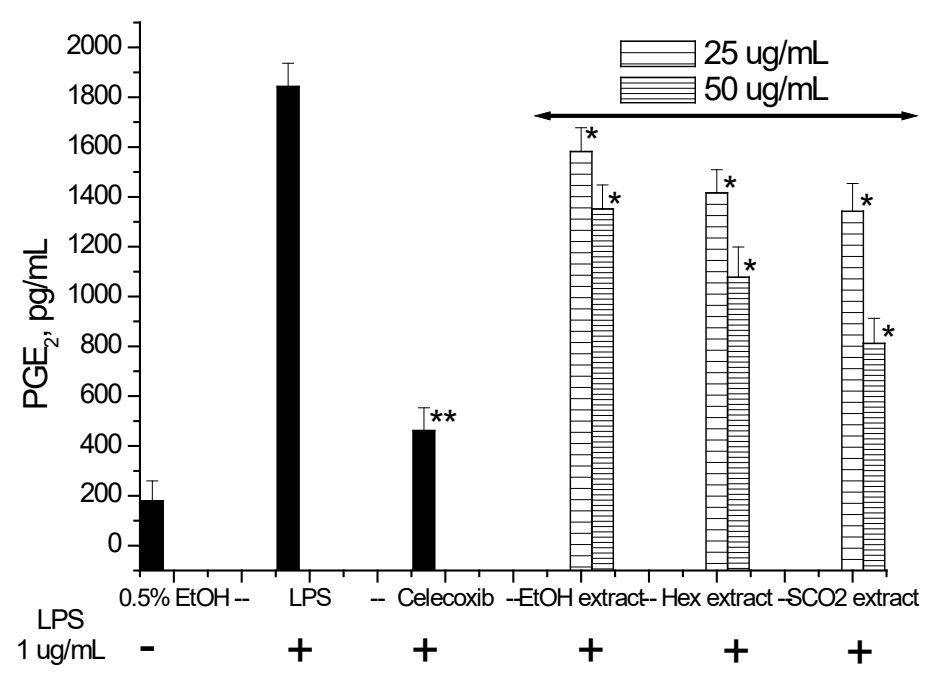

Figure 5 Effects of EtOH, Hex and $\mathrm{SCO}_{2}$ extracts on LPS induced PGE 2 production in RAW 264.7 cells. The cells were incubated with $0-50 \mu \mathrm{g} / \mathrm{mL}$ of extractions in the presence or absence of LPS $(1 \mu \mathrm{g} / \mathrm{mL})$ for $24 \mathrm{~h}$. Celecoxib was used as the positive control. ${ }^{*} P<0.05$ and ${ }^{* *} P<0.01$ indicated significant differences from the LPS-treated group.

The effects of the 3 different solvent extracts from Ipomoea pes-caprae on iNOS and COX-2 mRNA levels

Figure 6 represented the change in mRNA expression for iNOS and COX-2 based on their relative quantification values. LPS at $1 \mu \mathrm{g} / \mathrm{mL}$ induced a significant increase in iNOS and COX-2 mRNA expression as when compared to control cells without LPS. EtOH, Hex, and $\mathrm{SCO}_{2}$ extracts inhibited iNOS and COX-2 mRNA expression, and the results were consistent with the profile of the inhibition NO and $\mathrm{PGE}_{2}$ release. These data have also been confirmed at in vivo level, demonstrating the reduction of acute inflammation using the writhing test and carrageenan-induced pleurisy models in mice [2] and reduced chronic inflammation using the cotton pellet-induced granuloma model [3]. These results also agreed with Pongprayoon et al. [1] reporting that Ipomoea pes caprae extract contained active compounds such as eugenol exhibited anti-inflammation via the inhibition of prostaglandin activity. This supposed mechanism is similar to that of L-NAME and celecoxib, the drug used as the positive control, which mediated anti-inflammation via inhibiting $\mathrm{NO}$ and $\mathrm{PGE}_{2}$ productions. In addition, the results from previous studies demonstrated that iNOS has been correlated with the synthesis of $\mathrm{PGE}_{2}$ in activated macrophages with LPS and resulted in the production of inflammatory diseases [26]. Therefore, targeting the iNOS inhibitor and the COX-2 inhibitor might be beneficial in treating inflammatory-mediated diseases and cancer.

The inhibition of NO and PGE2 production is the main pillars in managing inflammatory and other painful conditions. Overproduction of inflammatory mediators such as NO and PGE2 is highly related to chronic inflammatory disease and will make the inflammatory microenvironment vulnerable to cancer progression. Key molecular cytokines linking inflammation to cancer are NO and PGE2 production in that cytokine signaling could increase microvascular density, leading to an increase of cancer cell proliferation and those by the inhibition of apoptosis [7]. In agreement with our previous studies, Hex and $\mathrm{SCO}_{2}$ extracts of Ipomoea pes-caprae induced apoptosis in $\mathrm{KB}$ cells and may be stated as a valid strategy for chemoprevention [12]. A review of the literature showed that the redox status has been closely linked with free radicals, inflammation and cancer. These findings and our previous studies of Ipomoea pescaprae extracts showed the most promising free radical scavenging and anti-inflammatory and anticancer activities, providing in vitro evidence.

The extraction of medicinal plants is an important activity in today's world. Among all the extracts, the relative effectiveness for anti-inflammation was $\mathrm{SCO}_{2}>\mathrm{Hex}>$ EtOH. For general bioactivity screening, the different solvents with different polarities were used in an arrangement from the non-polar to the polar ( $\left.\mathrm{Hex}>\mathrm{SCO}_{2}>\mathrm{EtOH}\right)$. In supercritical fluid extraction, carbon dioxide was inherently nonpolar solvent, and the addition of ethanol as co-solvents enhanced the solubility of polar molecules; 
accordingly, the $\mathrm{SCO}_{2}$ extract had both polar and non-polar substances. In addition, supercritical fluid extraction has gained popularity for speedy, contamination-free extraction and retrieval of various bioactive compounds [27]. Further, in accordance with our previous results, the chemical compositions of these extracts as compared by gas chromatography showed that $\mathrm{Hex}$ and $\mathrm{SCO}_{2}$ had comparable chemical composition patterns. However, their compositions had more ingredients than those obtained from EtOH extract [12]. In general, the mangrove plants often produce secondary metabolites under stressful high salt conditions. Therefore, it is not surprising that mangrove plants biosynthesis a wide range of secondary metabolites to treat several ailments, including inflammatory-related diseases. Thus, this study provides in vitro evidence for the use of Thai traditional plants, Ipomoea pes-caprae extracts, as antioxidant, antiinflammatory activities and confirm the traditional use of this plant toward dermatitis caused by jellyfish stings.
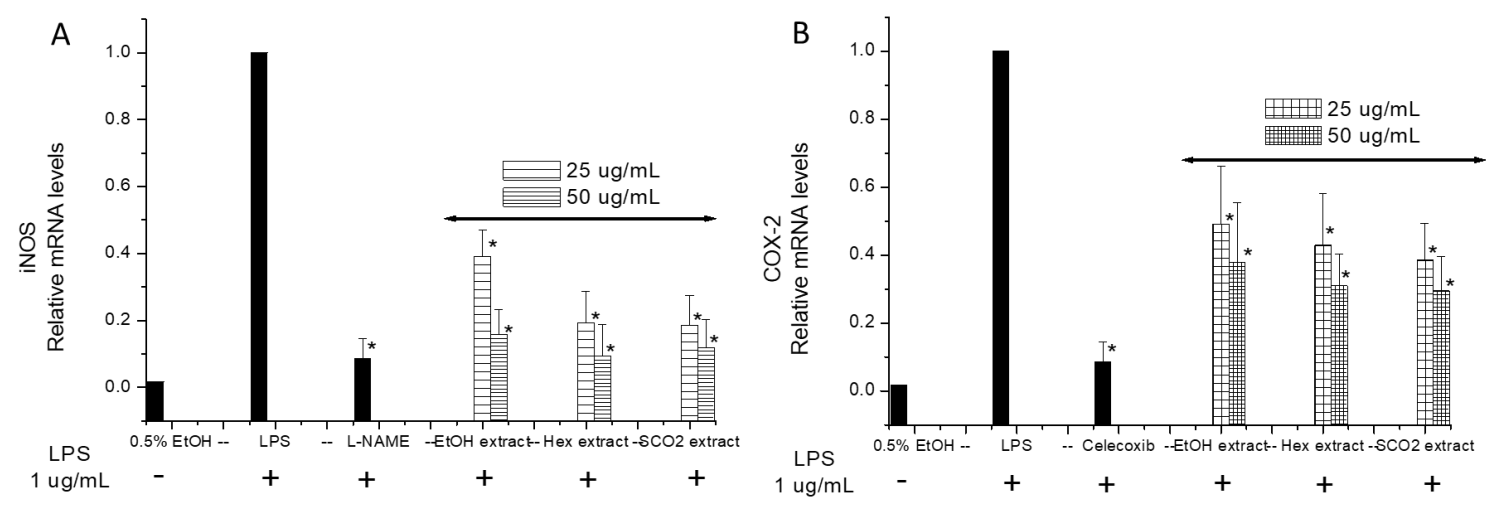

Figure 6 Effects of EtOH, Hex and $\mathrm{SCO}_{2}$ extracts on LPS induced iNOS (A) and COX-2 (B) mRNA expression in RAW 264.7 cells. The cells were incubated with $0-50 \mu \mathrm{g} / \mathrm{mL}$ of extractions in the presence or absence of LPS $(1 \mu \mathrm{g} / \mathrm{mL})$ for $24 \mathrm{~h} .{ }^{*} P<0.05$ indicated significant differences from the LPS-treated group.

\section{Conclusions}

$\mathrm{EtOH}, \mathrm{Hex}$, and $\mathrm{SCO}_{2}$ extracts of Ipomoea pes-caprae prepared by different extraction methods possessed significant antioxidant and anti-inflammatory activities at non-cytotoxic dose. These effects of Ipomoea pes-caprae extracts resulted from the synergistic effect of many phytochemicals compounds in this plant. $\mathrm{SCO}_{2}$ extract exhibited the strongest activities in scavenged DPPH radical, inhibited radicalmediated cellular oxidation and suppressed $\mathrm{NO}$ and $\mathrm{PGE}_{2}$ production through the regulation of iNOS and COX-2 expression at the mRNA level. Thus, these bioactive compounds contained in Ipomoea pescaprae may function as therapeutic candidates for various inflammatory related diseases.

\section{Acknowledgements}

This research work was supported by The National Research Council of Thailand, 2015.

\section{References}

[1] U Pongprayoon, P Baeckstrom, U Jacabsson, M Lindstrom and L Bohlin. Compounds inhibiting prostaglandin synthesis isolated from Ipomoea pes caprae. Planta Med. 1991; 57, 515-8.

[2] D Vieira, D Padoani, JDS Soares, J Adriano, VC Filho, MMD Souza, TMB Bresolin and AG Couto. Development of hydro-ethanolic extract of Ipomoea pescaprae using factorial design followed by antinociceptive and anti-inflammatory evaluation. Braz. J. Pharmacog. 2013; 23, 72-8.

[3] ND Venkataraman, WC Atlee, TP Prabhu and R Kannan. Anti-inflammatory potential of ethanolic extracts from aerial parts of Ipomeae pes-caprae (L.). R. Br. Using cotton pellet induced granuloma model. J. Appl. Pharm. Sci. 2013; 3, 061-3.

[4] MM de Souza, A Madeira, C Berti, R Krogh, RA Yunes and V Cechinel-Filho. Antinociceptive properties of the methanolic extract obtained from Ipomoea pes-caprae (L.) R. Br. $J$. Ethnopharmacol. 2000; 69, 85-90.

[5] CS Barth, HG T de Souza, LW Rocha, GF da Silva, MF Dos Anjos, VD Pastor, TM B Bresolin, AG Couto, JR Santin and NL M Quintão. Ipomoea pes-caprae (L.) R. Br (Convolvulaceae) relieved 
nociception and inflammation in mice - A topical herbal medicine against effects due to cnidarian venom-skin contact. J. Ethnopharmacol. 2017; 200, 156-64.

[6] P Arulselvan, MT Fard, WS Tan, S Gothai, S Fakurazi, ME Norhaizan and SS Kumar. Role of antioxidants and natural products in inflammation. Oxid. Med. Cell. Longev. 2016; 2016, 5276130.

[7] M Kumar, S Kumar and S Kaur. Role of ROS and COX-2/iNOS inhibition in cancer chemoprevention: A review. Phytochem. Rev. 2012; 11, 309-37.

[8] Z Liu, Z Ren, J Zhang, CC Chuang, E Kandaswamy, T Zhou and L Zuo. Role of ROS and nutritional antioxidants in human diseases. Front. Physiol. 2018.

[9] V Aggarwal, HS Tuli, A Varol, F Thakral, MB Yerer, K Sak, M Varol, A Jain, MA Khan and G Sethi. Role of reactive oxygen species in cancer progression: Molecular mechanisms and recent advancements. Biomolecules 2019; 9, 735.

[10] R Pereda-Miranda, E Escalante-Sa'nchez and C Escobedo-Marti'nez. Characterization of lipophilic pentasaccharides from beach Morning Glory (Ipomoea pes-caprae). J. Nat. Prod. 2005; 68, 226-30.

[11] A Manigauha, MD Kharya and N Ganesh. In vivo antitumor potential of Ipomoea pes-caprae on melanoma cancer. Pharmacogn. Mag. 2015; 11, 426-33.

[12] C Saengkhae, N Uawongyart and S Osiri. Cytotoxicity and apoptotic mechanisms of different solvent extracts from Ipomoea pes-caprae on human nasopharyngeal cells. Chula. Med. J. 2019; 63, 143-51.

[13] M Chatatikun and A Chiabchalard. Phytochemical screening and free radical scavenging activities of orange baby carrot and carrot (Daucus carota Linn.) root crude extracts. J. Chem. Pharmaceut. Res. 2013; 5, 97-102.

[14] CF Lin, KC Young, CH Bai, BC Yu, CT Ma, YC Chien, CL Chiang, CS Liao, HW Lai and CW Tsao. Rosiglitazone regulates anti-inflammation and growth inhibition via PTEN. Biomed Res. Int. 2014; 2014, 787924.

[15] P Kunnaja, W Kumsaiyai, K Punturee, A Siriphun and T Chatboonward. Inhibition of nitric oxide production and COX-2 protein expression in LPS-stimulated RAW 264.7 cells by the hexane fraction of Murdannia loriformis. J. Assoc. Med. Sci. 2019; 52, 103-11.

[16] CH Kang, YH Choi, IW Choi, JD Lee and GY Kim. Inhibition of lipopolysaccharide-induced iNOS, COX- 2, and TNF- $\alpha$ expression by aqueous extract of Orixa japonica in RAW 264.7 cells via suppression of NF- kB activity. Trop. J. Pharmaceut. Res. 2011; 10, 161-8.

[17] A Ocaña-Fuentes, E Arranz-Gutiérrez, FJ Señorans and G Reglero. Supercritical fluid extraction of oregano (Origanum vulgare) essentials oils: Anti-inflammatory properties based on cytokine response on THP-1 macrophages. Food Chem. Toxicol. 2010; 48, 1568-75.

[18] SK Jaganathan and E Supriyanto. Antiproliferative and molecular mechanism of eugenol-induced apoptosis in cancer cells. Molecules 2012; 17, 6290-304.

[19] F Fadilah, A Yanuar, A Arsianti, R Andrajati. Phenylpropanoids, eugenol scaffold and its derivatives as anticancer. Asian J. Pharmaceut. Clin. Res. 2017; 10, 41-6.

[20] C Escobedo-Mart1'nez and R Pereda-Miranda. Resin glycosides from Ipomoea pes-caprae. J. Nat. Prod. 2007; 70, 974-8.

[21] GN Sapkale, SM Patil, US Surwase and PK Bhatbhage. Supercritical fluid extraction. Int. J. Chem. Sci. 2010; 8, 729-43.

[22] D Banerjee, AK Hazra, T Seal, TK Sur, D Bhattacharya, J Ray, A Mukherjee and B Mukherjee. Antioxidant and anti-inflammatory activities of different solvent extracts and isolated compounds of Ipomoea pes-caprae (L) sweet of sunder ban mangrove eco-complex. Asian J. Chem. 2013; 25, 4997-5000.

[23] S Vijayalaxmi, SK Jayalakshmi and K Sreeramulu. Polyphenols from different agricultural residues: Extraction, identification and their antioxidant properties. J. Food Sci. Tech. 2015; 52, 2761-9.

[24] OA Castaneda, SC Lee, CT Ho and TC Huang. Macrophages in oxidative stress and models to evaluate the antioxidant function of dietary natural compounds. J. Food Drug Anal. 2017; 25, 1118.

[25] H Zhang and R Tsao. Dietary polyphenols, oxidative stress and antioxidant and anti-inflammatory effects. Curr. Opin. Food Sci. 2016; 8, 33-42.

[26] D Salvemini, SF Kim and V Mollace. Reciprocal regulation of the nitric oxide and cyclooxygenase pathway in pathophysiology: relevance and clinical implications. Am. J. Physiol. Regul. Integr. Comp. Physiol. 2013; 304, R473-R487.

[27] SD Manjare and K Dhingra. Supercritical fluids in separation and purification: A review. Mater. Sci. Tech. 2019; 2, 463-84. 